\title{
Autoimmune Thyroid Disease and Breast Cancer Prognosis
}

\author{
Tolga Özmen ${ }^{1}$, Bahadır Mahmut Güllüoğlu ${ }^{1}$, Cumhur Şevket Yegen ${ }^{1}$, Atilla Soran ${ }^{2}$ \\ ${ }^{1}$ Department of General Surgery, Marmara University Faculty of Medicine, İstanbul, Turkey \\ ${ }^{2}$ Department of General Surgery, Magee Womens Hospital of UPMC, Pittsburgh, ABD
}

\begin{abstract}
Objective: The association of breast cancer and thyroid autoimmunity has been suggested by many studies in the literature, but the causality still needed to be proven. With this study we aimed to search the correlation between thyroid autoimmunity and breast cancer prognostic factors.

Materials and Methods: To this prospective cohort study 200 consecutive breast cancer patients, who were operated in our clinic were included. Patients' serum thyroid hormone, anti-thyroglobuline (anti-TG) and anti-thyroid peroxidase (anti-TPO) levels and tumors' prognostic parameters (tumor size, axillary involvement, histological grade, lymphovascular invasion, receptor status, Ki-67 proliferation index) were collected. The correlation between serum thyroid autoantibody levels and tumor's prognostic factors were studied.

Results: The prevalence of thyroid autoimmunity (high levels of serum anti-TPO and/or anti-TG) was $18.5 \%$ ( $\mathrm{n}=37$ ). Patients with thyroid autoimmunity had a significant lower rate of axillary involvement and a lower rate of Ki-67 proliferation index ( $22 \%$ vs. $46 \%$ [p=0,007] and $12.73 \%$ vs. $20.72 \%$ $[\mathrm{p}=0.025]$, respectively) and were more commonly included to the "low-risk" group $(<14 \%)$ according to their Ki-67 scores $(68 \%$ vs. $46 \%$; $\mathrm{p}=0.015)$. Other parameters did not differ between the two groups.

Conclusion: We found a favorable correlation between thyroid autoimmunity and axillary involvement and also Ki-67 proliferation index score, which are two crucial and strongly predictive parameters of breast cancer prognoses. This supports the idea of thyroid autoimmunity being a favorable prognostic parameter. Further studies are necessary to investigate the reasons of protective or predictive effect of high thyroid peroxidase levels in breast cancer patients.
\end{abstract}

Keywords: Breast cancer, autoimmune thyroid disease, prognostic factors

\section{Introduction}

The higher prevalence of both benign thyroid diseases and breast cancer in women compared to men and their increased prevalence in the postmenopausal period suggest that certain shared factors may be influential in the etiology of these two diseases. Some studies determined that the prevalence of AITD (auto-immune thyroid disease) was higher among breast cancer patients (1-4). A recent meta-analysis reported a significant increase in the risk of breast cancer detection in a person with AITD [odds ratio (OR): 2.92] (5). As a consequent step, the researchers investigated whether the concomitance of AITD in breast cancer patients had an effect on the disease prognosis upon which they obtained conflicting results. While the concomitance of AITD was reported as a positive prognostic factor in some papers (6-10), other papers defended the contrary position $(2,11)$. This study investigated the correlation between AITD and breast cancer prognostic factors. The hypothesis of the study was constructed as follows: prognostic parameters are observed to be more positive in breast cancer patients with concomitant AITD and AITD constitutes a positive prognostic factor for breast cancer.

\section{Materials and Methods}

\section{Study Type and Population}

This study was planned as a prospective cohort study. The study population consisted of patients scheduled for surgery at our clinic with diagnosis of breast cancer. Within this cohort, patients with at least one of their thyroid autoantibodies at a high level were considered "AITD-positive" while patients with both thyroid autoantibodies at a high level were considered "AITD-negative."

This Orginal article was presented as the $18^{\text {th }}$ SIS World Congress on Breast Healthcare 16-19 October 2014, Orlando, Florida. 


\section{Table 1. Inclusion and exclusion criteria for the study}

\section{Study inclusion criteria:}

1. Having been diagnosed with histopathological breast cancer in the pre-operative period

2. Having accepted taking part in the study and providing patient consent

Study exclusion criteria:

1. Not agreeing to take part in the study

2. Stage 4 breast cancer diseases

3. Previous surgery due to thyroid disease or current drug therapy

\section{Ethics Committee Approval for the Study}

The approval from the Ethics Committee for this study was obtained from the "Research-Review Commission" of our hospital with the issue number B.30.2.MAR.0.01.02/AEK/750.

\section{Inclusion and Exclusion Criteria for the Study}

The patients who presented to our clinic for treatment with breast cancer diagnosis and met the study inclusion criteria were included in the study (Table 1). Before the patients were included in the study, their consents were received.

\section{Study objectives}

Primary objective of the study:

- To compare the prognostic and predictive parameters of breast cancer patients that has concomitant AITD (tumor stage, tumor size, axillary lymph node involvement, histological degree, lymphovascular invasion, hormone receptor status, c-erbB2 expression, multifocality/multicentricity) with breast cancer patients that do not have concomitant AITD.

Secondary objective of the study:

- Identification of AITD prevalence in breast cancer patients.

\section{Collection of Serum Specimens}

Before surgery, $10 \mathrm{cc}$ blood samples were collected from the patients in a yellow tube (tube containing a separator and a coagulation activator) and sent to the laboratory for analysis.

\section{Recorded and Measured Variables}

The demographic information of individuals included in the study (sex, age, menopausal status) and their serum thyroid hormone and antibody levels [thyroid stimulating hormone (TSH), free-T3 (s-T3), freet-T4 (s-T4), anti-thyroid peroxidase (anti-TPO), anti-thyroglobulin (anti-Tg)] was recorded. The upper limits in thyroid antibody levels were accepted as $34 \mathrm{IU} / \mathrm{mL}$ for anti-TPO and as $115 \mathrm{IU} / \mathrm{mL}$ for anti-TG. Patients with at least one of these values at a high level were considered AITD-positive. The normal ranges for TSH, s-T3 and s-T4 were accepted as 0.27-4.2 $\mathrm{uIU} / \mathrm{mL}, 1.8-4.6 \mathrm{pg} / \mathrm{dL}$ and $1-1.8 \mathrm{ng} / \mathrm{dL}$, respectively.

Additionally, the cancer stages of patients as per staging by American Joint Committee on Cancer (AJCC), tumor diameter, histological degree of the tumor as per the Modified Scarff-Bloom-Richardson grading system, lymphovascular invasion status, hormone (estrogen and pro- index, metastasis status in axillary lymph nodes and multicentricity/ multifocality were recorded based on their pathology reports. For all metastases larger than $0.2 \mathrm{~mm}$ in the axillary lymph nodes on the same side as the tumor, the axilla was considered positive $\left(\mathrm{N}_{+}\right)$. Tumoral invasion in all the lymphatic and vascular structures around the tumor was considered as lymphovascular invasion. The tumors observed to have estrogen and/or progesterone receptors in at least 5 out of 100 cells that examined were considered positive while cells observed with less than 5 receptors were considered negative. As for the c-erbB2 assessment, tumors identified to be $3+$ or $2+$ with immunohistochemical method and observed to have amplification according to the FISH (fuorescence in situ hybridisation) test were accepted c-erbB2-positive while other tumors were accepted c-erbB2. During molecular subtying classification, tumors that were estrogen receptor-positive and c-erbB2-negative were considered as "Luminal A", tumors that were estrogen receptor-positive, c-erbB2-positive with a high proliferation score as "Luminal B", tumors that were estrogen receptor-negative, but c-erbB2-positive as "Her-2 type" and tumors that were estrogen receptor-negative and c-erbB2-negative as "triple negative." In the Ki-67 proliferation index analysis, the immunohistochemical (IHC) staining method was used. The ratio of cancer cells that were stained with nuclear antigen $\mathrm{Ki}-67$ under light microscope to the total cancer cells was recorded as a percentage value. As accepted in the literature, those with an index value $<14 \%$ were accepted low risk (12).

\section{Statistical analysis}

The study data were recorded and statistically analyzed using the SPSS (Statistical Package for the Social Sciences) version 19 (IBM Corporation, New York, United States of America) software program. For the comparison of categorical data, the Chi-square test was used and for the comparison of perpetual data, the independent student $t$ test was used. During the analysis of categorical data, the "odds ratio (OR)" was also calculated and the OR remained within the $95 \%$ confidence interval. The results were illustrated as average value \pm standard deviation. For the analysis, a p value below 0.05 was considered significant.

\section{Findings}

\section{Demographic, Clinical and Pathological Findings}

Two hundred consecutive patients operated on at our clinic with the diagnosis of breast cancer between "1, June, 2012 and 1, June, 2014" were included in the study. All of the patients were female and the average age was calculated as $52.59 \pm 12.85$ [26-90]. Their average age at menarche was found as $13.44 \pm 2.87$ [11-14] years, average menopausal age as $47.31 \pm 4.42[37-55]$ years and average age at first pregnancy as $23.31 \pm 5.4$ [14-39] years. The rate of miscarriage among patients included in the study was $24.2 \%$ and the rate of abortion was $31.9 \%$. For menopausal patients, $10.8 \%$ of them had received hormone replacement therapy and $23.9 \%$ of them had breast cancer in their family history (Table 2).

When the thyroid hormone and autoantibody levels of the patients were examined, the autoimmunity prevalence was identified as $18.5 \%$ $(n=37)$. Twenty-four $(64.9 \%)$ of these 37 patients were found to be autoimmune euthyroidic, 8 of them (\%21.6) hyperthyroidic, 4 of them $(10.8 \%)$ subclinical hyperthyroidic and 1 (2.7\%) of them hyperthyroidic. Eight (4.9\%) out of 163 patients not observed to have any auto-immunities were observed as subclinical hyperthyroidic, 3 of them $(1.8 \%)$ as hyperthyroidic, 2 of them $(1.2 \%)$ as hyperthyroidic and 1 of them $(0.6 \%)$ as subclinical hyperthyroidic. The remaining 


\section{Table 2. Demographic characteristics of patients}

\begin{tabular}{lc} 
Age (average years \pm SD [range]) & $52.59 \pm 12.85$ [26-90] \\
$\begin{array}{l}\text { Age of menarche (average years } \pm S D \\
\text { [range]) }\end{array}$ & $13.44 \pm 2.87$ [11-14] \\
$\begin{array}{l}\text { Menopausal age (average years } \pm S D \\
\text { [range]) }\end{array}$ & $47.31 \pm 4.42$ [37-55] \\
$\begin{array}{l}\text { Age at first pregnancy (average years } \pm S D \\
\text { [range]) }\end{array}$ & $23.31 \pm 5.4[14-39]$ \\
Miscarriage rate (\%) & 24.2 \\
Abortion rate (\%) & 31.9 \\
Rate of having received HRT* (\%) & 10.8 \\
Rate of breast cancer in family history (\%) & 23.9 \\
\hline *HRT=hormone replacement therapy &
\end{tabular}

Table 3. Distribution of patients as per their thyroid functions

$\begin{array}{lc}\text { Autoimmunity }(+) & 24(64.9) \\ \text { euthyroidic } & 8(21.6) \\ \text { hyperthyroidic } & 4(10.8) \\ \text { subclinical hyperthyroidic } & 1(2.7) \\ \text { hyperthyroidic } & \\ \text { Autoimmunity (-) } & 149(91.5) \\ \text { euthyroidic } & 8(4.9) \\ \text { subclinical hyperthyroidic } & 3(1.8) \\ \text { hyperthyroidic } & 2(1.2) \\ \text { hyperthyroidic } & 1(0.6) \\ \text { subclinical hyperthyroidic } & \end{array}$

Table 4. Tumor characteristics

\begin{tabular}{llc}
\hline & & n (\%) \\
\hline \multirow{2}{*}{ Stage } & Stage 1 & $60(28.1)$ \\
& Stage 2 & $90(43.3)$ \\
& Stage 3 & $50(23.6)$ \\
Histological type & Invasive ductal carcinoma & $174(87)$ \\
& Invasive lobular carcinoma & $19(9.5)$ \\
Molecular sub-types & Other & $7(3.5)$ \\
& Luminal A & $104(51.7)$ \\
& Luminal B & $26(12.9)$ \\
& Her-2 & $22(11.4)$ \\
& Triple negative & $48(23.9)$
\end{tabular}

$149(91.5 \%)$ patients were observed to have normal thyroid autoantibody and hormone levels (Table 3 ).

A great majority of the patients $(\mathrm{n}=90)$ included in our study had stage II tumors, $87 \%$ had invasive ductal types and $9.5 \%$ had invasive lobu- lar cancers. Considering the molecular sub-types, $51.7 \%$ of them were observed to have Luminal A breast cancer and 23.9\% triple negative breast cancer (Table 4).

\section{Effect of thyroid autoimmunity on the breast cancer prognostic factors}

The rate of axillary involvement in patients observed to have autoimmunity was significantly lower as compared to those not observed to have autoimmunity ( $22 \%$ vs. $46 \%$; p=0.007; OR:0.328 [0.141$0.761])$. While the Ki-67 proliferation index average was $12.73 \%$ [0$80]$ in patients with accompanying autoimmunity was, it was calculated as $20.72 \%$ [0-90] for other patients $(p=0.025)$. Considering the rates of inclusion in the low risk group $(<14 \%)$ as per Ki-67 index), $68 \%$ of the patients with accompanying autoimmunity were in the low risk group whereas this rate was calculated as $46 \%$ in the other group ( $\mathrm{p}=0.015$; OR:2.565 [1.178-5.585]). No significant differences were identified between two groups with respect to other prognostic factors (Table 5).

\section{Discussion and Conclusions}

In this prospective cohort study investigating the effect of thyroid autoimmunity on breast cancer prognostic and predictive factors, the rate of axillary lymph nodule involvement in breast cancer patients with accompanying autoimmunity was observed to be significantly lower in comparison with other patients. The average Ki-67 proliferation index in breast cancer patients with accompanying autoimmunity was identified to be significantly lower than the other patient group and more patients were included in the low-risk group with respect to Ki-67 proliferation index. No differences were observed between two groups in terms of other parameters.

The fact that the target population of both breast cancer and thyroid diseases is women and that its incidence peaks in the post-menopausal period led the researchers to investigate the potential association between these two diseases and several benign thyroid diseases to date have been association with breast cancer (1-4). A recently published meta-analysis reviewed all these studies and concluded that there was an association between breast cancer and autoimmune thyroid disease (5). These were then following by studies comparing the thyroid autoimmunity and breast cancer prognostic parameters (6-10). Certain publications defended that the rising anti-TPO levels in breast cancer patients with accompanying autoimmunity constituted a positive parameter in terms of cancer prognosis. These papers specified that rising antibody levels constituted a parameter at least as important as axillary lymph node involvement and tumor size $(7,8)$. However, a study that was published alter claimed that autoimmunity was a negative prognostic factor for breast cancer. This study conducted by Cengiz et al. (11) emphasized that lymphovascular invasion and axillary lymph node involvement rates were higher in breast cancer patients with accompanying immunity. In our study, axillary lymph node involvement rate $(22 \%)$ in breast cancer patients with accompanying autoimmunity was observed to be significantly lower in comparison with the other group (46\%). The lower rate of axillary lymph node involvement in patients with autoimmunity $(+)$ could be attributed to the high level of anti-TPO in this group. Even though thyroid autoantibodies are known to play an important role on cellular cytotoxicity in thyroid, a similar effect has not yet been demonstrated for the breast tissue (13). Both breast tissue and thyroid tissue transmit iodine from their membranes to the inside of cells (1). Therefore, both tissues demonstrate antigenic characteristics due to sodium-iodide-symporter canals and 
Table 5. Comparison of autoimmunity and breast cancer prognostic parameters

\begin{tabular}{|c|c|c|c|c|}
\hline & & $\begin{array}{l}\text { Autoimmunity present } \\
\qquad(n=37)\end{array}$ & $\begin{array}{l}\text { Autoimmunity none } \\
\qquad(n=163)\end{array}$ & $\mathbf{p}$ \\
\hline Tumor diameter: mm (avg \pm SD) & & $24.97 \pm 14.55$ & $24.60 \pm 13.82$ & 0,889 \\
\hline \multirow[t]{2}{*}{ Axillary involvement: $n(\%)$} & Positive & $8(22)$ & $75(46)$ & $\begin{array}{c}0.007 \\
\mathrm{OR}^{*}=0.328 \\
{[0.141-0.761]}\end{array}$ \\
\hline & Negative & $29(78)$ & $88(54)$ & 0.482 \\
\hline \multirow[t]{2}{*}{ Histological Grade: n(\%) } & $1 \& 2$ & $21(56)$ & $80(49)$ & \\
\hline & 3 & $16(44)$ & $83(51)$ & \\
\hline \multirow[t]{2}{*}{ LVP**; n(\%) } & Positive & $16(43)$ & $94(58)$ & 0.116 \\
\hline & Negative & $21(57)$ & $69(42)$ & \\
\hline Ki-67; \% avg[range] & & $12.73[0-80]$ & $20.72[0-90]$ & 0.025 \\
\hline \multirow[t]{2}{*}{ Ki- $67<14$ vs. $\geq 14 ;$ n(\%) } & $<14$ & $25(68)$ & $75(46)$ & 0.015 \\
\hline & $\geq 14$ & $12(32)$ & $88(54)$ & $\begin{array}{c}\mathrm{OR}^{*}=2.565 \\
{[1.178-5.585]}\end{array}$ \\
\hline \multirow[t]{4}{*}{ Molecular sub-type: $n(\%)$} & Luminal A & $17(46)$ & $86(52)$ & 0.446 \\
\hline & Luminal B & $3(8)$ & $23(14)$ & \\
\hline & Her-2 (+) & $6(16)$ & $17(10)$ & \\
\hline & Basal type & $11(30)$ & $37(24)$ & \\
\hline \multirow[t]{3}{*}{ Number of tumor foci: n(\%) } & multifocality & $1(3)$ & $18(11)$ & 0.273 \\
\hline & multicentricity & $2(5)$ & $11(7)$ & \\
\hline & unifocality & $34(92)$ & $135(82)$ & \\
\hline
\end{tabular}

peroxidase activity $(14,15)$. However, anti-TPO antibodies have not yet been proven to engage in interaction with receptors located on cancerous breast tissue and the mechanism through which it reduces axillary lymph node involvement should be the subject of future studies.

Tumor proliferation has a very important role in predicting its recurrence risk $(16,17)$. Ki-67, which was defined by Gerdes et al. in 1980 s, is a nuclear protein associated with cellular proliferation (18) and several studies to date have demonstrated high $\mathrm{Ki}-67$ values to be a poor prognostic parameter showing tumor aggressiveness and it has been observed that patients with high Ki-67 values have lower survival rates (19-22). In our study, Ki-67 proliferation index was observed to be significantly lower in the patient population with accompanying autoimmunity (12.73\% vs. $20.72 \%)$. Significantly more patients in the group of patients with autoimmunity were in the group with low risk in terms of Ki-67 index (<14\%) (68\% vs. 46\%). The fact that proliferation is lower in patients with accompanying autoimmunity is a positive prognostic parameter and supports the hypothesis in our study. The development mechanism of this association is not yet known. To the best of our knowledge, K-67 index was compared with autoimmunity for the first time in this study in the literature with meaningful results obtained.

No reliable data demonstrating the prevalence of autoimmune thyroid diseases in Turkey have yet been reported. This prevalence is at the level of 1-2\% in the United States of America $(23,24)$. The frequency of AITD in breast cancer patients progressing with significant or subclinical hyperthyroidism was reported as 30\% while high thyroid anti- ducted on 100 breast cancer patients and 100 healthy control group subjects, the high thyroid autoantibody level prevalence was identified as $25 \%$ for cancer patients and as $18 \%$ for healthy subjects (6). In this study, which has been conducted on 200 women with breast cancer, high thyroid autoantibody level prevalence was calculated as $18.5 \%$ in breast cancer women. Identification of the prevalence of autoimmune diseases in healthy subjects and breast cancer patients in Turkey through community-based studies to be conducted with larger cohorts would provide remarkable contribution to the literature.

The strength of this study is that it is one of the two largest studies in terms of sample size among prospective studies investigating this subject in the literature. Another strong point of this study is that it compared Ki-67 mutation index and autoimmunity. As for the weakness of the study, it is the fact that we did not have 5-year-survival rate values while making interpretations about breast cancer prognosis. However, it is planned to determine the 5-year-survival values of the cohort and then to identify whether autoimmunity makes a difference by way of contribution to the literature.

The lower rate of axillary involvement in breast cancer patients with accompanying AITD and the lower Ki-67 infiltration index of the tumors in this group according to the results of this study may suggest that thyroid autoimmunity may accompany positive prognostic factors with respect to breast cancer. For that reason, we are convinced that screening persons diagnosed with breast cancer for autoantibody levels would be useful in that it may not only enable diagnosis and timely treatment of the concomitant AITD, if any, but it may also offer information on prognostic factors for breast cancer. 
Ethics Committee Approval: Ethics committee approval was received for this study.

Informed Consent: Written informed consent was obtained from patients who participated in this study.

Peer-review: Externally peer-reviewed.

Author Contributions: Concept - T.Ö.; Design - T.Ö.; Supervision - B.M.G., C.S.Y., A.S.; Funding - B.M.G., C.S.Y.; Materials - T.Ö., B.M.G; Data Collection and/or Processing - T.Ö., A.S.; Analysis and/or Interpretation - T.Ö., B.M.G, C.S.Y, A.S.; Literature Review - T.Ö.; Writer - T.Ö.; Critical Review - B.M.G, A.S., C.S.Y; Other - T.Ö.

Conflict of Interest: No conflict of interest was declared by the authors.

Financial Disclosure: The authors declared that this study has received no financial support.

\section{References}

1. Giani G, Fierabracci P, Bonacci R, Gigliotti A, Campani D, De Negri F, Cecchetti D, Martino E, Pinchera A. Relation between breast cancer and thyroid disease: Revelance of autoimmune thyroid disorders in breast malignancy. J Clin Endocrinol Metabol 1996; 81:990-994. (PMID: 8772562)

2. Jiskra J, Barkmanova J, Limanova Z. Thyroid autoimmunity occurs more frequently in women with breast cancer compared to women with colorectal cancer and controls but it has no impact on relapse-free and overall survival. Oncol Rep 2007; 18:1603-1611. (PMID: 17982651) [CrossRef]

3. Turken O, Narin Y, Demirbas S, Onde ME, Sayan O, KandemIr EG, YaylacI M, Ozturk A. Breast cancer in association with thyroid disorders. Breast Cancer Res 2003; 5:110-113. (PMID: 12927040) [CrossRef]

4. Giustarini E, Pinchera A, Fierabracci P, Roncella M, Fustaino L, Mammoli C, Giani C. Thyroid autoimmunity in patients with malignant and benign breast diseases before surgery. Eur J Endocrinol 2006; 5:645-649. (PMID:16645010) [CrossRef]

5. Hardefeldt PJ, Eslick GD, Edirimanne S. Benign thyroid disease is associated with breast cancer: a meta-analysis. Breast Cancer Res Treat 2012; 133:1169-1177. (PMID: 22434524) [CrossRef]

6. Ozmen T, Akkiprik M, Kaya H, Gulluoglu BM. Breast cancer and autoimmune thyroid disease relationship: Can hormonal factors or thyroglobulin gene polymorphism be the common factor? J Breast Health 2014; 10:35-41. [CrossRef]

7. Smyth PPA, Shering SG, Kilbane MT, Murray MJ, McDermott EW, Smith DF, O'Higgins NJ. Serum thyroid peroxidase autoantibodies, thyroid volume and outcome in breast cancer. Clin Endocr Metab 1988; 8:2711-2716. (PMID: 9709936)

8. Smyth PP. Autoimmune thyroid disease and breast cancer: a chance association. J Endocrinol Invest 2000; 23:42-43. (PMID: 10698051) [CrossRef]

9. Goldman MB, Monson RR, Maloof F. Benign thyroid diseases and the risk of death from breast cancer. Oncology 1992; 49:461-466. (PMID: 1465285) [CrossRef]

10. Fiore E, Giustarini E, Mammoli C, Fragomeni F, Campani D, Muller I, Pinchera A, Giani C. Favorable predictive value of thyroid autoimmunity in high aggressive breast cancer. J Endocrinol Invest 2007; 30:734-738. (PMID: 17993764) [CrossRef]

11. Cengiz O, Bozkurt B, Unal B, Yildirim O, Karabeyoglu M, Eroglu A, Kocer B, Ulas M. The relationship between prognostic factors of breast cancer and thyroid disorders in Turkish women. J Surg Oncol 2004; 87:19-25. (PMID: 15221915) [CrossRef]
12. Goldhirsch A, Wood WC, Coates AS, Gelber RD, Thurlimann B, Senn HJ. Strategies for subtypes-dealing with the diversity of breast cancer: highlights of the St. Gallen International Expert Consensus on the Primary Therapy of Early Breast Cancer 2011. Ann Oncol 2011; 22:17361747. (PMID: 21709140) [CrossRef]

13. Rodien PM, Madec AM, Ruf J. Antibody dependent cell-mediated cytotoxicity in autoimmune thyroid disease: relationship to antithyroperoxidase antibodies. J Clin Endocrinol Metab 1996; 81:2595-2600. (PMID: 8675583) [CrossRef]

14. Kogai T, Taki K, Brent GA. Enhancement of sodium/iodide symporter expression in thyroid and breast cancer. Endocr Relat Cancer 2006; 13:797-826. (PMID: 16954431) [CrossRef]

15. Kim SS, Kim IJ, Kim SJ, Lee JY, Bae YT, Jeon YK, Kim BH, Kim YK. Incidental diffuse thyroid 18F-FDG uptake related to autoimmune thyroiditis may be a favorable prognostic factor in advanced breast cancer. J Nucl Med 2012; 12:1855-1862. (PMID: 23139085) [CrossRef]

16. Hanahan D, Weinberg RA. The hallmarks of cancer. Cell 2000; 1:57-70. (PMID: 10647931) [CrossRef]

17. Milde-Langosch K, Karn T, Muller V, Witzel I, Rody A, Schmidt M, Wirtz RM. Validity of the proliferation markers Ki67, TOP2A, and RacGAP1 in molecular subgroups of breast cancer. Breast Cancer Res Treat 2013; 1:57-67. (PMID: 23135572) [CrossRef]

18. Gerdes J, Schwab U, Lemke H, Stein H. Production of a mouse monoclonal antibody reactive with a human nuclear antigen associated with cell proliferation. Int J Cancer 1983; 31:13-20. (PMID: 6339421) [CrossRef]

19. Stuart-Harris R, Caldas C, Pinder SE, Pharoah P. Proliferation markers and survival in early breast cancer: a systematic review and meta-analysis of 85 studies in 32,825 patients. Breast 2008; 17:323-334. (PMID: 18455396) [CrossRef]

20. de Azambuja E, Cardoso F, de Castro G, Colozza M Jr, Mano MS, Durbecq V, Sotiriou C, Larsimont D, Piccart-Gebhart MJ, Paesmans M. Ki-67 as prognostic marker in early breast cancer: a meta-analysis of published studies involving 12,155 patients. Br J Cancer 2007; 96:15041513. (PMID: 17453008) [CrossRef]

21. Viale G, Giobbie-Hurder A, Regan MM, Coates AS, Mastropasqua MG, Dell'Orto P, Maiorano E, MacGrogan G, Braye SG, Ohlschlegel C et al. Prognostic and predictive value of centrally reviewed Ki-67 labeling index in postmenopausal women with endocrine-responsive breast cancer: results from Breast International Group Trial 1-98 comparing adjuvant tamoxifen with letrozole. J Clin Oncol 2008; 26:5569-5575. (PMID: 18981464) [CrossRef]

22. Jacquemier J, Charafe-Jauffret E, Monville F, Esterni B, Extra JM, Houvenaeghel G, Xerri L, Bertucci F, Birnbaum D. Association of GATA3, P53, Ki67 status and vascular peritumoral invasion are strongly prognostic in luminal breast cancer. Breast Cancer Res 2009; 11:23. (PMID: 19405945) [CrossRef]

23. Jacobson DL, Gange SJ, Rose NR, Graham NM. Epidemiology and estimated population burden of selected autoimmune diseases in the United States. Clin Immunol Immunopathol 1997; 84:223-243. (PMID: 9281381) [CrossRef]

24. Hollowell JG, Staehling NW, Flanders WD, Hannon WH, Gunter EW, Spencer CA, Braverman LE. Serum TSH, T (4), and thyroid antibodies in the United States population (1988 to 1994): National Health and Nutrition Examination Survey (NHANES III). J Clin Endocrinol Metab 2002; 87:489-499. (PMID: 11836274) [CrossRef]

25. Shering SG, Zbar AP, Moriatry M. Thyroid disorders and breast cancer. Eur J Cancer Prev 1996; 5:504-506. (PMID: 9061284) 